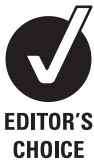

1 Paediatric Epidemiology Group, Division of

Epidemiology and Biostatistics, University of Leeds, Leeds,

UK; ${ }^{2}$ Martin House Children's Hospice, Grove Road, Clifford, Boston Spa, Wetherby, UK

Correspondence to Dr Lorna K Taylor, Paediatric Epidemiology Group, Division of

Epidemiology and Biostatistics, Room 8.49, Worsley Building, Clarendon Way, University of Leeds, Leeds LS2 9JT, UK;

I.k.fraser@leeds.ac.uk

Accepted 13 October 2009

\title{
Palliative care in Yorkshire, UK 1987-2008: survival and mortality in a hospice
}

\author{
L K Taylor, ${ }^{1}$ M Miller, ${ }^{2}$ T Joffe, ${ }^{1}$ R C Parslow, J Aldridge, ${ }^{2}$ C C Bailey, ${ }^{2}$ P A McKinney ${ }^{1}$
}

\begin{abstract}
Objective: To provide new epidemiological evidence base of information on models of hospice care for children and young adults.
\end{abstract}

Design: Retrospective cohort study of children referred to a hospice.

Setting: Martin House Children's and Young Person's Hospice in Boston Spa, North Yorkshire, UK.

Participants: All children who had been referred for care at Martin House Children's Hospice since it opened in August 1987, until May 2008.

Main outcome measures: Demographic profiles and survival times overall and by diagnostic group classified by the Association of Children's Palliative Care (ACT) Diagnostic Categories, calculated using the KaplanMeier and log rank pair-wise methodology.

Results: Over a 20-year period, 1554 children aged from birth to 19 years were referred to Martin House, of whom $89.5 \%$ (mean age 7.45 years) were accepted. The deprivation profile, referral source and distribution of diagnoses of these children have changed over time with recently increasing numbers of non-progressive disorders (ACT category 4). The ethnicity profile has changed with an increase in the numbers of South Asian children. The overall mean survival time was 5.6 years (95\% CI 5.1 to 6.1 ) but this differed by ACT category. Diagnostic category was significantly associated with differing survival patterns.

Conclusions: There are a disproportionate number of children from areas of higher deprivation being referred for palliative care services. There has been a recent increase in the number of children from South Asian families being referred to palliative care services in Yorkshire. Survival times for children and young people receiving care from a hospice can vary from hours and days to more than 20 years.

\section{INTRODUCTION}

Paediatric palliative care differs in many ways from adult palliative care. In adult medicine, the majority of patients requiring palliative care have a primary diagnosis of cancer. ${ }^{1}$ There is little evidence available on palliative care services for children and young people. ${ }^{2} 3$ Better data collection has been identified as a priority by the UK Department of Health ${ }^{4}$ in order to facilitate evidence-based commissioning.

Martin House is a children's hospice located in Yorkshire. It cares for children and young people with life-threatening or life-limiting conditions diagnosed before the age of 19 years until the age of 35 years within hospice and the community.

This unique study presents over 20 years of data on children and young people who have received palliative care at Martin House with the aim of

\section{What is already known on this topic}

- Children's palliative care is a growing specialty, but there are limited epidemiological data currently available.

What this study adds

- There are a disproportionate number of children from deprived areas and children from South Asian backgrounds being referred to palliative care services.

- The length of involvement with a children's hospice is highly variable and can last for over 20 years.

providing a new epidemiological evidence base that will facilitate improved planning of service provision for this group.

\section{METHODS}

This retrospective cohort study exploited a preexisting database of details of children and young people recorded as being referred to Martin House for palliative care since its opening in 1987 until the data analysis in May 2008. The database contained demographic (age of referral, sex and ethnicity), diagnostic and clinical information about the children and their families. The data were systematically checked for outliers, inconsistencies and missing data, but as the database has evolved over the years, not all variables were complete for all referrals.

The main variables of interest were age at referral (in years), age at death (in years, if occurred), year of referral, diagnostic groupings (Martin House and ACT categories - see table 1), referral source (family, GP, social work, hospital staff, community staff, other) and whether they were accepted for care by Martin House. Deprivation scores (Townsend) ${ }^{5}$ were assigned to each child based on their validated postcode of the last known residence. ${ }^{6}$

Ethnicity (South Asian or not) was classified using two South Asian name-recognition software packages (SANGRA ${ }^{7}$ and Nam Pehchan ${ }^{8}$ ). Children were classified as South Asian if both programmes identified them as so. Manual checking for obvious 
Table 1 Diagnostic categories for paediatric palliative care

\begin{tabular}{ll}
\hline Martin House categories & $\begin{array}{l}\text { Association of Children's Palliative Care } \\
\text { categories }\end{array}$ \\
\hline 1. Chromosomal & $\begin{array}{l}\text { Group 1: Life-threatening conditions for } \\
\text { 2. CNS }\end{array}$ \\
which curative treatment may be feasible \\
but cNS progressive & services may be necessary when treatment \\
4. Cardiac & fails (eg, cancer, irreversible organ failure) \\
5. Metabolic & Group 2: Conditions where premature death \\
6. MPS & is inevitable, where there may be long \\
7. Duchenne muscular & periods of intensive treatment aimed at \\
dystrophy & prolonging life and allowing participation in \\
8. Spinal muscular atrophy & normal activities (eg, cystic fibrosis) \\
9. CNS oncology & Group 3: Progressive conditions without \\
10. Oncology & curative treatment options, where \\
11. Other & treatment is exclusively palliative and may \\
& commonly extend over many years (eg, \\
& Batten disease, MPS, muscular dystrophy) \\
& Group 4: Irreversible but non-progressive \\
& conditions causing severe disability leading \\
& to susceptibility to health complications and \\
& likelihood of premature death (eg, severe \\
& cerebral palsy, multiple disabilities such as \\
& following brain or spinal cord insult)
\end{tabular}

CNS, central nervous system; MPS, mucopolysaccharidoses.

errors was undertaken. This methodology does not allow for more detailed ethnicity (Indian, Pakistani or Bangladeshi) to be reliably assigned.

A key variable was the primary diagnosis, and in order to analyse the data sensibly, these diagnoses were grouped together. Martin House has its own diagnostic groups (table 1) which are clinically useful but not necessarily distinct, and their 11 categories resulted in small numbers for some analyses. To reduce the problem of small numbers, the Association for Children's Palliative Care (ACT) and RCPCH in 1997 (table 1$)^{9}$ categories were used for the analysis.

Ethical approval was obtained from Leeds University Faculty of Medicine and Health Ethics Committee.

\section{STATISTICAL ANALYSIS}

All referred children ( $\mathrm{n}=1554)$ were included in the descriptive statistics, but the survival analysis was restricted to those known to be alive or had died on the censor date (May 2008) ( $n=1163$ ) (see figure 1). All analyses were performed using SPSS version 15.0.

Kruskal-Wallis tests were performed for between-group differences for more than two groups. The means of two groups were compared using the $t$ test.

A survival analysis was performed using the Kaplan-Meier method, and statistical differences between the curves were explored using a log rank pairwise analysis. Analyses were stratified by 5-year time periods (1984-1988, 1989-1993, 1994-1998, 1999-2003, 2004-2008).

\section{RESULTS}

Figure 1 shows the number of referrals and their subsequent involvement with Martin House. Ten per cent of referred children were not accepted by Martin House. Twenty per cent of accepted children were alive in May 2008 under the care of the Martin House team. The relatively small proportion of children who had 'moved on' either had moved geographically to another service or were no longer considered to be palliative (eg, received transplant organ). Those in the 'not involved' group were accepted for care by Martin House, but the family chose not to take up the care offered.

The original referrals $(n=1554)$ revealed a $60 \%$ male: $40 \%$ female split, with a mean age of 7.45 years (SD 5.75 years). Ethnicity data were recorded for only $18.4 \%$ (286) of the referrals. Running SANGRA and Nam Pehchan resulted in 201 children identified as South Asian. Manual checking removed four of these cases and added 17. This resulted in 214 (13.8\%) children being classified as South Asian.

Time trends in the patterns of referrals are given in table 2 by age at referral, sex, ethnicity, deprivation score, the source of referral and the ACT diagnostic category. There was a significant decrease in the mean age of referral over time, from 8.21 years in 1984-1988 to 6.87 years in the latest time period (Kruskal-Wallis, $\chi^{2} 28.5$, df 4, $\mathrm{p}<0.001$ ). There are a higher proportion of males in every year group.

The number of children with a South Asian background has increased from $3 \%$ since opening to $26.4 \%$ in the period 2004-2008. The rate of increase has been particularly rapid over the past 10 years.

Alive - alive and receiving

care from palliative care team as of 20 May 2008

Not involved - families offered care by the palliative care team but have not accepted that care

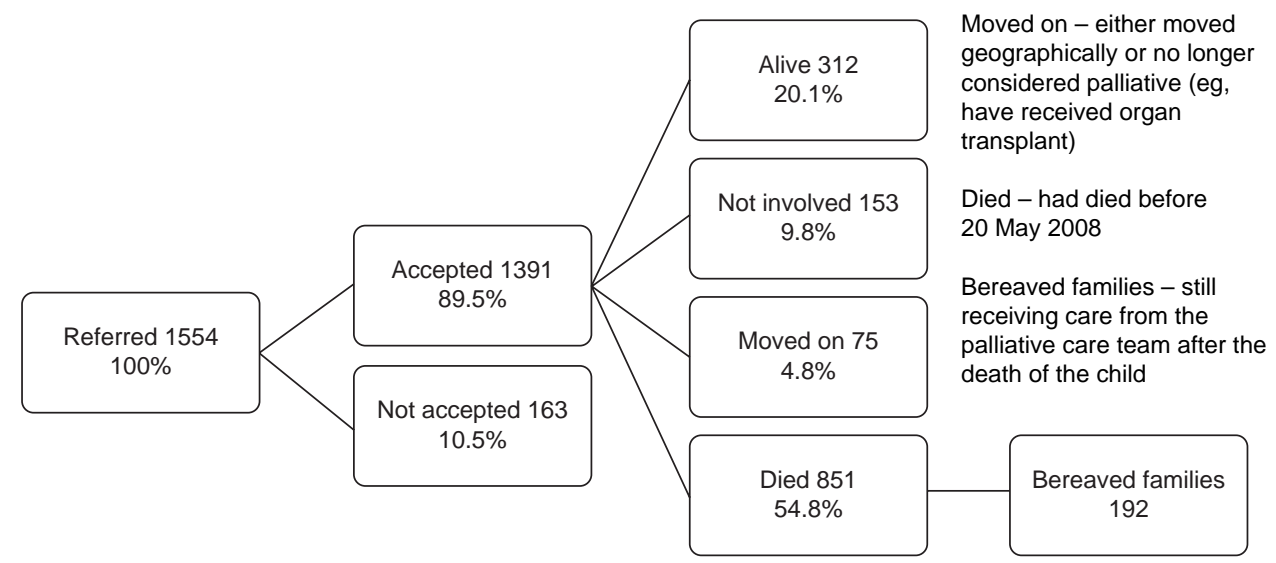

Figure 1 Status of patients referred to Martin House by 20 May 2008. 
Table 2 Trends in 5-year groups of age, sex, ethnicity, deprivation, referral source and diagnostic categories of referrals to children's hospice

\begin{tabular}{|c|c|c|c|c|c|c|}
\hline & $1984-1988(n=133)$ & $1989-1993(n=437)$ & $1994-1998(n=309)$ & $1999-2003(n=331)$ & $2004-2008(n=344)$ & Total $(n=1554)$ \\
\hline No of deaths & 34 & 176 & 211 & 197 & 234 & 852 \\
\hline \multicolumn{7}{|l|}{ Age (years) } \\
\hline Minimum* & -0.29 & -0.01 & -0.001 & -0.001 & -0.12 & -0.29 \\
\hline Maximum & 23.59 & 23.63 & 19.05 & 25.51 & 26.51 & 26.51 \\
\hline Meant & 8.21 & 7.92 & 7.34 & 7.49 & 6.67 & 7.45 \\
\hline SD & 5.86 & 5.48 & 7.48 & 5.74 & 6.27 & 5.75 \\
\hline Female & $57(42.9 \%)$ & $166(37.9 \%)$ & $110(35.7 \%)$ & $153(46.1 \%)$ & $139(40.3 \%)$ & $625(40.1 \%)$ \\
\hline Male & $75(56.4 \%)$ & $264(60.3 \%)$ & $198(64.3 \%)$ & 178 (53.9\%) & $204(59.1 \%)$ & $920(59.6 \%)$ \\
\hline Not known & $1(0.8 \%)$ & $7(1.6 \%)$ & $1(0.3 \%)$ & 0 & $1(0.3 \%)$ & $10(0.6 \%)$ \\
\hline \multicolumn{7}{|l|}{ Ethnicity } \\
\hline South Asian & $4(3 \%)$ & $25(5.7 \%)$ & $21(6.8 \%)$ & $73(22.0 \%)$ & $91(26.4 \%)$ & $214(13.8 \%)$ \\
\hline \multicolumn{7}{|l|}{ Townsend category } \\
\hline 5 (most deprived) & $25(18.8 \%)$ & $95(21.7 \%)$ & $95(30.7 \%)$ & $88(26.6 \%)$ & $104(30.2 \%)$ & $407(26.2 \%)$ \\
\hline Not known & $21(15.8 \%)$ & $82(18.8 \%)$ & $17(5.5 \%)$ & $16(4.8 \%)$ & $14(4.1 \%)$ & $150(9.7 \%)$ \\
\hline \multicolumn{7}{|l|}{ Referral source } \\
\hline Family & $47(35.3 \%)$ & $85(19.5 \%)$ & $40(12.9 \%)$ & $26(7.9 \%)$ & $23(6.7 \%)$ & $221(14.2 \%)$ \\
\hline GP & $11(8.3 \%)$ & $20(4.6 \%)$ & $6(1.9 \%)$ & $7(2.1 \%)$ & $8(2.3 \%)$ & $52(3.3 \%)$ \\
\hline Social work & $13(9.8 \%)$ & $106(24.3 \%)$ & 56 (18.1\%) & $55(16.6 \%)$ & $37(10.8 \%)$ & $267(17.2 \%)$ \\
\hline Hospital & $20(15.0 \%)$ & $107(24.5 \%)$ & $131(42.4 \%)$ & $138(41.2 \%)$ & $150(43.6 \%)$ & $546(35.1 \%)$ \\
\hline Community & $18(13.5 \%)$ & $66(15.1 \%)$ & $63(20.4 \%)$ & $96(29.0 \%)$ & 105 (30.5\%) & $348(22.4 \%)$ \\
\hline Other & $23(17.3 \%)$ & $50(11.4 \%)$ & $13(4.2 \%)$ & $9(2.7 \%)$ & $16(4.7 \%)$ & $111(7.1 \%)$ \\
\hline Not known & $1(0.8 \%)$ & $4(0.9 \%)$ & 0 & 0 & $5(1.5 \%)$ & $10(0.6 \%)$ \\
\hline \multicolumn{7}{|c|}{ Association of Children's Palliative Care category } \\
\hline
\end{tabular}

*There are occasional antenatal referrals which account for the negative ages.

$t p<0.001$ for Kruskal-Wallis test for trend.

In the earliest period, more children living in the most affluent areas were referred, but thereafter around a third of referrals $(30.2 \%)$ were children living in the most deprived areas.

Initially, most of the referrals came from individual families, but more recently hospital and community services have been the main source of referrals. There was a peak in referrals from the social work service when Martin House first opened.

The majority of children referred have been classified as ACT category 3 up until the most recent year group where the number of category 4 children has increased (table 2).

Age at referral also showed significant differences by ACT category (data not shown), with the oldest in group 1 (mainly oncology) (mean age 8.74 years) and the youngest in group 4 (eg, cerebral palsy) (mean age 5.79 years) (Kruskal-Wallis, $\chi^{2}$ 71.0, df $3, \mathrm{p}<0.001)$.

Table 3 shows the comparison between children who are accepted or not accepted for care at Martin House. There is no significant difference in their mean age ( $t$ test, $p=0.767)$. There are more females than males who are not accepted $\left(\chi^{2} 9.12\right.$, $\mathrm{p}=0.003)$. This excess remains when boys with Duchenne muscular dystrophy (DMD; $\mathrm{n}=197$ ) are removed from the analysis $\left(\chi^{2} 4.34, p=0.037\right)$. The distribution of ACT categories is different in the accepted versus not accepted group; the majority of children accepted are ACT category 3, while in the not accepted group $50.3 \%$ are classified as ACT category 4. There are no differences in the distribution of deprivation in the two groups. There are an excess of family referrals that are not accepted.

\section{SURVIVAL ANALYSIS}

In the subgroup analysis of 1163 children, 312 of whom were alive and 851 of whom died, the mean survival time was 5.61 years (95\% CI 5.14 to 6.07), median 2.20 years (IOR 0.24 to 8.79). The shortest survival times are in group 1 of the ACT category (mean 1.51 years) with group 3 children having the longest involvement with Martin House (7.09 years).

Figure 2 show the survival times by ACT diagnostic groups. The differences by ACT category (table 1(b)) are highlighted with the group 1 children having the most acute curve and shortest mean length of involvement. The ACT category curves are statistically significantly different from each other using log rank pairwise comparisons $\left(\chi^{2} 41.1, p<0.001 ; \chi^{2} 269.3\right.$ $\left.p<0.001 ; \chi^{2} 8.531, p=0.003\right)$ apart from groups 2 and $4\left(\chi^{2} 1.73\right.$, $\mathrm{p}=0.188)$.

\section{DISCUSSION}

This paper presents novel clinical and demographic information on children referred for palliative care to one of the first 
Table 3 Demographic, diagnostic and referral characteristics of children referred to Martin House Hospice who were and were not accepted for care

\begin{tabular}{|c|c|c|}
\hline & Accepted $(n=1390)$ & Not accepted $(n=164)$ \\
\hline \multicolumn{3}{|l|}{ Age (years) } \\
\hline Minimum* & -0.29 & -0.001 \\
\hline Maximum & 26.51 & 23.63 \\
\hline Mean & 7.43 & 7.57 \\
\hline SD & 5.71 & 5.99 \\
\hline \multicolumn{3}{|l|}{ Sex } \\
\hline Female & 542 (39.0\%) & $82(50.0 \%)$ \\
\hline Male & $842(60.5 \%)$ & 77 (47.0\%) \\
\hline Not known & $6(0.4 \%)$ & $5(3.0 \%)$ \\
\hline \multicolumn{3}{|c|}{$\begin{array}{l}\text { Association of Children's } \\
\text { Palliative Care category }\end{array}$} \\
\hline 1 & $281(20.2 \%)$ & $11(6.7 \%)$ \\
\hline 2 & $171(12.3 \%)$ & $31(19.0 \%)$ \\
\hline 3 & $656(47.2 \%)$ & $37(22.7 \%)$ \\
\hline 4 & $280(20.1 \%)$ & $85(51.6 \%)$ \\
\hline Not known & $2(0.1 \%)$ & 0 \\
\hline \multicolumn{3}{|l|}{ Townsend category } \\
\hline 1 (least deprived) & 208 (15.0\%) & $26(16.0 \%)$ \\
\hline 2 & $241(17.3 \%)$ & $23(14.1 \%)$ \\
\hline 3 & 225 (16.2\%) & $28(17.2 \%)$ \\
\hline 4 & $220(15.8 \%)$ & $26(16.0 \%)$ \\
\hline 5 (most deprived) & $364(26.2 \%)$ & $43(26.4 \%)$ \\
\hline Not known & 132 (9.5\%) & $18(11.0 \%)$ \\
\hline \multicolumn{3}{|l|}{ Year group } \\
\hline 1984-1988 & $120(8.6 \%)$ & $13(8.0 \%)$ \\
\hline 1989-1993 & $383(27.6 \%)$ & $55(33.1 \%)$ \\
\hline 1994-1998 & $290(20.8 \%)$ & 19 (11.7\%) \\
\hline 1999-2003 & $301(21.7 \%)$ & $29(17.8 \%)$ \\
\hline $2004-2008$ & $296(21.3 \%)$ & $48(29.4 \%)$ \\
\hline Not known & 0 & 0 \\
\hline \multicolumn{3}{|l|}{ Referral group } \\
\hline Family & 185 (13.3\%) & $36(22.1 \%)$ \\
\hline GP & $43(3.1 \%)$ & $9(5.5 \%)$ \\
\hline Social work & $238(17.1 \%)$ & $29(17.8 \%)$ \\
\hline Hospital & $510(36.7 \%)$ & $36(22.1 \%)$ \\
\hline Community & $311(22.4 \%)$ & $37(22.7 \%)$ \\
\hline Other & $97(7.0 \%)$ & $14(8.6 \%)$ \\
\hline Not known & $2(0.1 \%)$ & $3(1.8 \%)$ \\
\hline
\end{tabular}

*There are occasional antenatal referrals which account for the negative ages.

children's hospices set up in the UK. The results highlight that most but not all children who are referred are accepted as appropriate to receive palliative care.

The decrease in the mean age at referral could be due to increased involvement with neonatal patients. The boys with DMD partly explain the excess of boys in this dataset.

The ethnicity analysis showed a striking increase over the last 10 years in the proportion of South Asian children being referred to Martin House. This may be due to more understanding and acceptance of the concept of palliative care in these communities, and also there has been an increase in South Asian births relative to the rest of the population. ${ }^{10}$ The estimated 2007 South Asian population of children aged $0-15$ years in Yorkshire and the Humber is $8.6 \% .{ }^{11}$ Using these figures as denominators in the most recent year group, 20042008 , the rate of palliative care in South Asian Children is 1.09 per 1000 compared with 0.28 per 1000 in non-South Asian Children. We did not have any information on consanguinity among the families referred to Martin House.

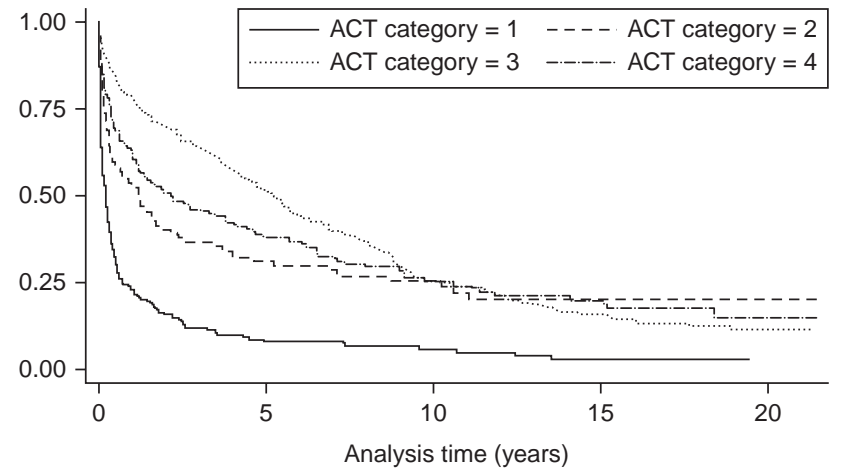

Figure 2 Survival by Association of Children's Palliative Care (ACT) diagnostic categories.

Referral trends have recently changed with an increase in the number of children who would be classified as ACT category 4-for example, cerebral palsy. Whether this is purely an increased awareness that palliative care may help such children or a real increase in prevalence of children with such disorders is unknown.

The skewed distribution of deprivation in children at Martin House, showing higher numbers living in deprived areas, may be due to a number of factors. First, the Townsend Score only looks at four factors, but due to the historical nature of the dataset the index of multiple deprivation $2004^{12}$ may not be valid. The financial burden of having a child with a lifethreatening or life-limiting condition may have an impact on a family's deprivation status, or it may be that children from deprived backgrounds have an increased incidence of diagnoses which may require palliative care; a study from the US concluded that although deprived families were less likely to report a chronic illness in their child, the prevalence of chronic illnesses was significantly higher in the more socially deprived children. ${ }^{13}$

The change in referral source from family and social work in the early period to those from health professionals in hospital and community services may be due to those professionals being more willing to refer earlier on in the disease process.

Some but not all of the differences between the children who were accepted or not accepted for care can be explained. Children in ACT category 4 often have cerebral palsy with no life-shortening complications and therefore would not be accepted for care, but there is no clear explanation for the gender differences between the two groups once the boys with DMD have been removed.

With no other published data on survival times in paediatric palliative care found in the literature, the survival curves shown in figure 2 fill the information gap recently identified as key to improving services. ${ }^{3}$ The length of time a child is under the care of hospice services is highly variable, with some young people receiving care for over 20 years. In some groups of children, especially those with an oncology diagnosis, the length of involvement can be measured in days and weeks, as opposed to months and years. Overall, this differs from adult palliative care where, for example, an Australian study found that the median length of involvement was 54 days. ${ }^{1}$

This study has limitations in that the data available for analysis in this study were retrospective and, in some cases, were missing for some children. The information stored in the electronic database was not validated against the children's medical records. In addition, children who have never been 
or were no longer under the care of Martin House could not be included in the survival analysis, as their death status was unknown.

\section{CONCLUSIONS}

There are a disproportionate number of children from areas of higher deprivation being referred for palliative care services.

There has been a recent increase in the number of children from South Asian families being referred to palliative care services in Yorkshire.

There are more children in ACT category 4 (eg, cerebral palsy) in the group of children not accepted for palliative care.

Survival times for children and young people receiving care from a hospice can vary from hours and days to more than 20 years.

Acknowledgements: Thanks to L Hill, for starting the database, the Trustees at Martin House Children's and Young People's Hospice, for funding this study, and all the Team at Martin House, past and present.

Funding: This study was funded by Martin House Children and Young People's Hospice (Charity No 517919).

Competing interests: None.

Ethics approval: Ethics approval was provided by the Medicine \& Health Faculty Research Ethics Committee, University of Leeds.

Provenance and peer review: Not commissioned; externally peer reviewed.

\section{REFERENCES}

1. Good PD, Cavenagh J, Ravenscroft PJ. Survival after enrollment in an Australian sspalliative care program. J Pain Symptom Manage 2004;27:310-15.

2. Linton JM, Feudtner C. What accounts for differences or disparities in pediatric palliative and end-of-life care? A systematic review focusing on possible multilevel mechanisms. Pediatrics 2008;122:574-82.

3. Craft A, Killen S. Palliative care service for children and young people in England. Crown, London, 2007.

4. Department of Health. Better care: better lives. Crown, London, 2008.

5. Phillimore $\mathbf{P}$, Beattie $A$, Townsend $\mathbf{P}$. Widening inequality of health in northern England, 1981-91. BMJ 1994;308:1125-8.

6. Office for National Statistics, All Fields Postcode Directory (computer file). ESRC/JISC Census Programme, the Economic and Social Data Service (ESDS) and the UK Data Archive. University of Essex, 2005.

7. Nanchahal K, Mangtani P, Alston M, et al. Development and validation of a computerised South Asian Names and Group Recognition Algorithm (SANGRA) for use in British health-related studies. J Public Health Med 2001;23:278-85.

8. Bradford Health Authority and City of Bradford Metropolitan District Council. Nam pehchan: a program to identify and analyse South Asian names V.2.1. City of Bradford Metropolitan District Council, 2002.

9. ACT/RCPCH. A guide to the development of Children's Palliative Care Services. 1997 ISBN: 1900954060

10. Office for National Statistics (2005) Mortality Statistics. Childhood, infant and perinatal. Series DH3 no 36. London: Office for National Statistics. http://www.doh.gov.uk/downloads/theme health/Dh3 2003/DH3no36.pdf (Accessed 5 January 2009).

11. Office of National Statistics. http://www.statistics.gov.uk/StatBase/Product asp?vlnk=1423 (accessed 23 August 2009)

12. Index of Multiple Deprivation. 2004. http://www.communities.gov.uk (accessed 10 January 2009).

13. Newacheck PW. Poverty and childhood chronic illness. Arch Pediatr Adolesc Med 1994:148:1143-9. 